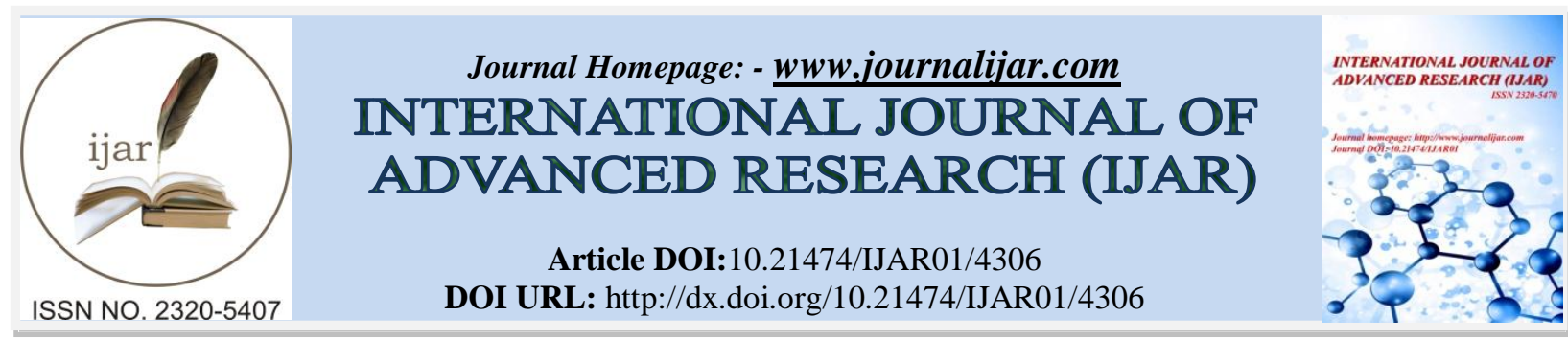

RESEARCH ARTICLE

\title{
APPLICATION OF UNIVERSAL MULTIPURPOSE MODULES OF INDUSTRIAL DISINTEGRATORS/ACTIVATORSFOR THE PROCESSING OF CEREALS AND POTATOES INTO STARCH PRODUCTS.
}

\author{
A. V. Kulakov ${ }^{1}$, V. A. Rantsev-Kartinov ${ }^{2}$ and V. M. Tyutyunnik ${ }^{3}$. \\ 1. Expert-analytical Centre of the Ministry of Education and Science of the Russian Federation, Moscow, Russia. \\ 2. Kurchatov Institute, Moscow, Russia. \\ 3. International Information Nobel Centre (IINC), Tambov, Russia.
}

\section{Manuscript Info}

\section{Manuscript History}

Received: 20 March 2017

Final Accepted: 25 April 2017

Published: May 2017

Key words:-

Universal Multipurpose Modules, disintegration/activation of crops, fine product.

\section{Abstract}

Universal Multipurpose Modules (UMM) was designed by the authors, which used for disintegration/activation of starch from potato tubers and grains of cereal crops in the dry fine product. UMM have the efficiency per unit of final product almost 200 times higher than the known apparatus, 6 times lower power consumption, almost an order of magnitude smaller material requirement, and are the quietest. The main technical result is controlled density increase of magnetic energy in working zones described sample of UMM. The results of the experiment for obtaining starch from raw jelly potatoes (potato squash) depending on the time of their grinding in UMM showed $56.3 \%$ starch after receiving a six-minute disintegration of potato squash (in excess of 2.5 times from known in modern production). Cost recovery is approximately 100 hours of the equipment work; the profitability of the use of the new grinding technology is $100-500 \%$.

Copy Right, IJAR, 2017,. All rights reserved.

\section{Introduction:-}

We wrote earlier $[1,2]$ on the establishment of new states of matter. We discuss here the practical application of this theory.

Green plants (under the influence of UV light from carbon dioxide and water) to produce glucose, which is a universal source of energy for all living things in the world: $6 \mathrm{CO}_{2}+6 \mathrm{H}_{2} \mathrm{O} \rightarrow \mathrm{C}_{6} \mathrm{H}_{12} \mathrm{O}_{6}+6 \mathrm{O}_{2}$. In turn, the glucose formed in green plants during photosynthesis, losing water, turns by polymerization into starch, which accumulates in the form of grains as a substitute substance of plants: $\mathrm{nC}_{6} \mathrm{H}_{12} \mathrm{O}_{6} \rightarrow\left(\mathrm{C}_{6} \mathrm{H}_{10} \mathrm{O}_{5}\right)_{\mathrm{n}}+\mathrm{nH}_{2} \mathrm{O}$. The accumulation of starch in plants can be written as: $6 \mathrm{nCO}_{2}+5 \mathrm{nH}_{2} \mathrm{O} \rightarrow\left(\mathrm{C}_{6} \mathrm{H}_{10} \mathrm{O}_{5}\right)_{\mathrm{n}}+6 \mathrm{nO}_{2}$.

The starch content of vegetable raw materials may vary from $22 \%$ (in potato tubers) to $60-80 \%$ (in beans, cereals).

Modern technologies of extracting starch from vegetable raw materials allow achieving high technical and economic indicators. However, the direct use of starch is limited, both for food and for technical purposes. There is a higher demand for starch processing products, which include, first and foremost, starch treacle, which is a saturated solution of a mixture of glucose, maltose and complex oligosaccharides. Technology of production of starch syrup is acid, enzymatic, or mixed hydrolysis of starch to achieve the specified value of a glucose equivalent mixture. To a 
large extent consumer and technological characteristics of molasses are determined by its chemical composition and, above all, dry matter distribution of molasses by size. If the maximum of distribution shifted to low-molecular compounds, we say about high-sugar molasses; molasses with high distribution in oligosaccharides area, we referred to as low-sugar molasses.

Acid hydrolysis process requires complex technological schemes. Technological processes are accompanied by the formation of impurities, including colorants, for subsequent removal of which requires considerable production resources.

Enzymatic hydrolysis allows get treacle with further composition of molecular masses. But the process of hydrolysis requires considerable time and energy resources. This saves the need for subsequent heat treatment of hydrolysate, which inevitably leads to the formation of dyes. The purity of this molasses is reduced due to remaining in its composition of deactivated enzymes that in the process of further use molasses, for example in the confectionery production, can lead to the formation of melanoids.

The final concentration of molasses in vacuum devices maximizes dry matter content of not more than $78.5 \%$. Thus, we are forced to carry (simultaneously with the valuable dry substances) $21.5 \%$ water when transporting molasses; this reduces technical and economic performance of the whole production chain enterprises, manufacturing and using eat molasses as raw material.

\section{Technological problem:-}

The disintegration of the starch molecules to fit, capable to enter into biochemical reactions with the receptor cavity, while creating a sweet incentive, is the actual task of technologists, even since the Kirchhoff. Given the variance is obtained by chemical (biochemical) fragmentation of starch molecules in liquid medium, since water is a necessary party to the reaction in both cases. The necessary activation energy of the hydrolysis reaction is usually receives at the expense of external sources of energy, in the form of hydrolysates heating.

However, the energy required for the reaction of starch molecule fragmentation, you can pass to starch grains by direct mechanical action. To do this, you must use mechanical disintegrators (crushers), which can provide a sufficient probability of collisions of individual starch grains and their fragments with frequency and energy that sufficient for mechanical destruction of the starch molecules. Disc disintegrators used for these purposes so far cannot provide the required level of energy supply to particles of starch.

\section{Research methodology and UMM Design:-}

The authors suggest using their device to solve the technical challenges, which received the common name Universal Multipurpose Modules (UMM) [3]. UMM, being more energy efficient, and can have very high efficiency in the processes described above. Versatility and high efficiency of UMM in this case due to: a) lots and activity processes in their working areas, such as crushing by means of "compressed kick", ultrasound (when handling liquid medium); b) high density of magnetic induction energy in their working area (if $\mathrm{B} \sim 10^{4} \mathrm{HS}, \mathrm{W} \sim 410^{5} \mathrm{~J} / \mathrm{m}^{3}$ ), hundreds of times greater than the density of the energy in the work areas of other similar devices (ball, hammer rotary and planetary mills); c) almost $100 \%$ EFFICIENCY; d) low material capacity.

UMM have almost 200 times higher efficiency per unit of final product, in 6 times lower power consumption, almost an order of magnitude less in material capacity, and are the quietest, compared with modern imported aggregates, which are used for fine grinding in food industry.

Controlled increase of magnetic energy density in working areas of one of the samples of UMM is the main technical result, which was sent to the attention of the authors [3]. This increase in energy density due to the following factors:

a. optimization design of magnetic inductor, assembled from six separate u-shaped cores with electromagnetic coils, which was made from copper tubes, refrigerated pass transformer oil flow;

b. higher value of magnetic induction in the working area of the device (up to three);

c. use of materials with high coercive force for actuating elements.

The effectiveness of the proposed devices is also caused by the physical and chemical activation of particles in it. UMM specifications are given in table 1 . 
Table 1:- Technical characteristics of UMM is based on one module.

\begin{tabular}{|l|c|}
\hline Performance (leak or spill), $\mathrm{m}^{3} / \mathrm{h}$ & 15 \\
\hline Pipe diameter, $\mathrm{m}$ & 0,1 \\
\hline Power supply requirement & $220 / 380 \mathrm{~V} ; 50-60 \mathrm{~Hz}$ \\
\hline Dimensions (height, width, length), $\mathrm{m}$ & $1 \times 1 \times 1$ \\
\hline Power, KW & $1,5-3,0-$ active \\
& $30-40-$ reactive \\
\hline Mass, $\mathrm{kg}$ & $500-750$ \\
\hline
\end{tabular}

The concept of the UMM is shown at Fig.1.
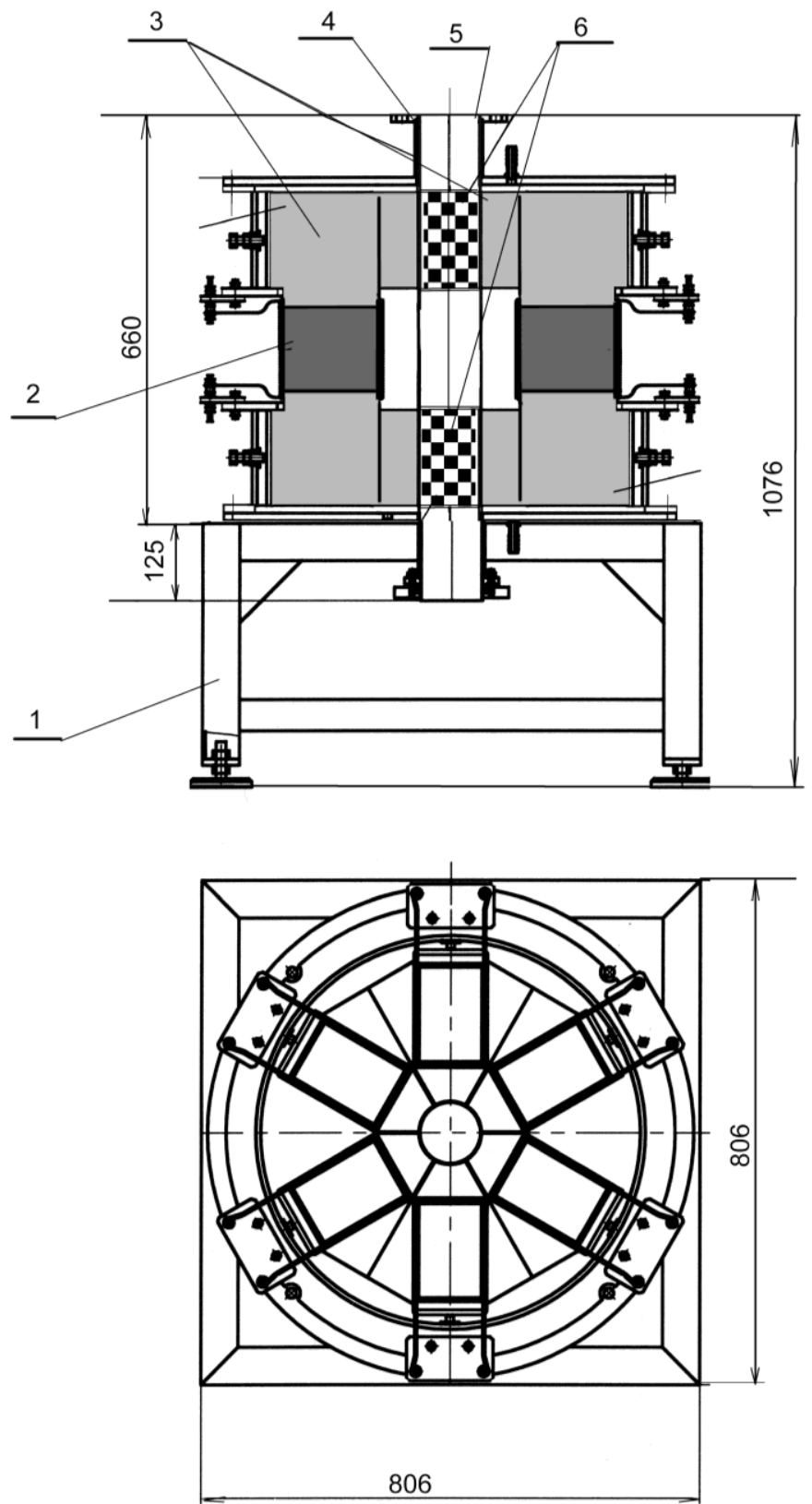

Figure 1:- The concept of UMM: 1 - rack, (chrome-nickel-titanium alloy); 2 - solenoid coils; 3 - inductor; 4 - principal trumpet; 5 - bushing (chrome-nickel-titanium alloy) with work areas; 6 - drop zones with actuating mediums.

UMM set in parallel for increased performance. The authors show that (when grinding in UMM) profitability grows with increased initial dispersion of source material. 
The proposed technology can be used to directly obtain the dry mix products of disintegration of the starch grains. Such a product can be called "dry molasses", and the degree of dispersion can be adjusted by changing the intensity and duration of the shock impact. This starch (after its disintegration to a specified level) can also serve as a substrate for further efficient enzymatic hydrolysis. A key feature in these apparatus is the high degree of grinding, since the process of starch hydrolysis under the influence of, say, enzymes is purely superficial; but because its effectiveness is growing rapidly with increasing fineness of the original product, which is proportional to the square of the particle density of the source product per unit of its mass. UMM properties are manifested in this mechanism, which devices are as activators of chemical processes. Efficiency gains can be attributed to the transition to nanotechnology that increases the homogenization of the slurry of cornstarch particles due to their eponymous charge, which allows us to process evenly around the volume flow of hydrolysis.

\section{Results and Discussion:-}

Experiment for obtaining starch from raw jelly potatoes (potato squash) depending on the grinding time at UMM was held with the UMM sample, calculated and created us with participation of the employees of the Russian Scientific Research Institute of starch products. The results of the experiment are shown in table 2.

Table 2:- The results of the experiment.

\begin{tabular}{|c|c|c|c|c|}
\hline $\begin{array}{c}\text { Name of raw material } \\
\text { (duration of disintegration) }\end{array}$ & $\begin{array}{l}\text { Large pulp, } \\
\mathrm{g} / \%\end{array}$ & $\begin{array}{l}\text { Small pulp, } \\
\mathrm{g} / \%\end{array}$ & Starch, g/\% & $\begin{array}{c}\text { Dry matter } \\
\text { weight, g/\% }\end{array}$ \\
\hline Corn porridge KO-5 (4 min.) & $6,03 / 22,9$ & $1,32 / 5,0$ & 18,99/72,1 & $26,33 / 100$ \\
\hline Potato squash KO-3 (2 min.) & $1,55 / 63,8$ & $0,16 / 6,6$ & $0,72 / \mathbf{3 0 , 6}$ & $2,43 / 100$ \\
\hline Potato squash $\mathrm{KO}-4$ (2 min.) & $1,95 / 62,3$ & $0,06 / 1,9$ & $1,11 / 35,6$ & $3,13 / 100$ \\
\hline Potato squash KO-6 (4 min.) & $2,513 / 57,1$ & $0,10 / 2,3$ & $1,79 / 40,7$ & $4,4 / 100$ \\
\hline Potato squash KO-8 (6 min.) & $0,86 / 41,2$ & $0,06 / 3,0$ & $1,17 / 56,0$ & $2,09 / 100$ \\
\hline Potato squash KO-10 (6 min.) & $0,87 / 38,1$ & $0,13 / 5,6$ & $1,29 / 56,3$ & $2,28 / 100$ \\
\hline
\end{tabular}

It is known that the content of starch in corn are only $65 \%$, and $22 \%$ are in potatoes. Unique features of UMM are illustrates by receiving of $56.3 \%$ starch after a six-minute disintegration of potato squash (in excess of 2.5 times from known in industry). The amount of starch is usually determined by Evers, on the starch polarization. Obviously, not only grain was grinded in our case, but also the starch; and hydrolysis took place more fully. There are other possible causes, but again connected with the increase of starch molecules' surface and intensification of reactions. Our hypothesis on the possibility of obtaining "dry molasses" found indirect confirmation.

Preliminary calculations show that the economic efficiency of the UMM utilization for grinding is grows when the profitability of the use of other types of mills is falls. In our technology, cost recovery is approximately 100 hours of work of the unit. Depending on the technical tasks to be solved, the profitability of the use of the new technology of grinding can range from 100 to $500 \%$ and above.

The proposed universal multipurpose module is a multifunctional effective device capable to resolve a wide range of technological challenges. These tasks (only in the area of food production) are: obtaining supersaturated solutions, mixing different kinds of flour, dispersion of bark and wood, biological activation of water, reduced the content of salts of heavy metals and soluble gases in it, use UMM as oil mill and to obtain the margarine and mayonnaise.

\section{References:-}

1. Kulakov A.V., Tyutyunnik V.M. New Approach to the Plasma Quantum Condensate, as a New State of Matter. International Journal of Current Research, 2017, Vol.9, No.3, pp.47699-47703.

2. Kulakov A.V., Tyutyunnik V.M. Solid phase plasma ultraviolet laser. International Journal of Advanced Research, 2017, Vol.5, No.4, pp.271-273. DOI 10.21474/IJAR01/3805.

3. Kulakov A.V., Runtsev-Kartinov V.A. Universal module of industrial shredders/activators. Patent Russia, No.161751, 03.03.2015. 